\title{
Features of cancer in teenagers and young adults in primary care: a population-based nested case-control study
}

\author{
R M Dommett ${ }^{\star 1,2}$, M T Redaniel ${ }^{3}$, M C G Stevens ${ }^{2}$, W Hamilton ${ }^{4,5}$ and R M Martin ${ }^{3,5}$ \\ ${ }^{1}$ School of Clinical Sciences, University of Bristol, Level 6 UHB Education Centre, Upper Maudlin Street, Bristol BS2 8AE, UK; \\ ${ }^{2}$ Department of Paediatric Oncology, Bristol Royal Hospital for Children, Upper Maudlin Street, Bristol BS2 8BJ, UK; ${ }^{3}$ School \\ of Social and Community Medicine, University of Bristol, Canynge Hallm, 39 Whatley Road, Bristol BS8 2PS, UK and ${ }^{4}$ University of \\ Exeter Medical School, Veysey Building, Exeter EX2 4SG, UK
}

Background: Teenagers and young adults (TYA, 15-24 years) diagnosed with cancer report repeated visits to primary care before referral. We investigated associations of symptoms and consultation frequency in primary care with TYA cancers.

Methods: Population-based, case-control study was carried out using data from the Clinical Practice Research Datalink (CPRD). A total of 1064 TYA diagnosed with cancer were matched to 13206 controls. Symptoms independently associated with specific cancers were identified. Likelihood ratios (LRs) and positive predictive values (PPVs) were calculated.

Results: In the 3 months before diagnosis, 397 (42.9\%) cases consulted $\geqslant 4$ times vs 593(11.5\%) controls (odds ratio (OR): 12.1; $95 \% \mathrm{Cl}: 9.7,15.1)$, yielding a PPV for any cancer of $0.018 \%$. The LR of lymphoma with a head/neck mass was $434(95 \% \mathrm{Cl}: 60,3158)$, with a PPV of $0.5 \%$. Corresponding figures in other cancers included - LR of leukaemia with lymphadenopathy (any site): 29 (95\% Cl: 8, 112), PPV 0.015\%; LR of CNS tumour with seizure: 56 (95\% Cl: 19, 163), PPV 0.024\%; and LR of sarcoma with lump/mass/swelling: 79 (95\% Cl: 24, 264), PPV 0.042\%.

Conclusion: Teenagers and young adults with cancer consulted more frequently than controls in the 3 months before diagnosis. Primary care features of cancer match secondary care reports, but were of very low risk; nonetheless, some features increased the likelihood of cancer substantially and should be taken seriously when assessing TYA.

Teenagers and young adults (TYA, 15-24 years) with cancer frequently report repeated visits to primary care before referral for investigation (Smith et al, 2007). Improving early diagnosis is a priority for TYA (Smith et al, 2007), reflected in UK cancer policy (Department of Health, 2007, 2011). Delayed diagnosis reduces the confidence of patients and parents in their doctor (Dixon-Woods et al, 2001; Larsen et al, 2011), but its impact on survival in TYA is unknown.

Potential cancer diagnoses are diverse in this age group, early symptoms are often nonspecific, may be explained by more common illnesses and, because cancer in TYAs is rare (Birch et al,
2002), are low on the list of differential diagnoses for a general practitioner (GP). The aim of this study was to investigate the risk of cancer in TYA presenting to primary care with symptoms and/ or increased consultation frequency.

\section{METHODS}

Study design. This was a population-based, case-control study nested within a cohort of TYA registered with the UK Clinical Practice Research Datalink (CPRD) (www.cprd.com). The CPRD is

\footnotetext{
*Correspondence: Dr RM Dommett; E-mail: R.Dommett@bris.ac.uk
}

${ }^{5}$ These two authors contributed equally to this work. 
a prospectively gathered, anonymised database that holds longitudinal administrative, clinical and prescribing records (including all consultations and diagnoses) of 11 million patients, from over 600 general practices across the UK (covering approximately $8 \%$ of the population; Clinical Practice Research Datalink, 2011). Data from the CPRD has been used in a number of studies to identify and quantify the symptoms of cancer (Hamilton et al, 2009; Shephard et al, 2012; Stapley et al, 2012; Dommett et al, 2012, 2013).

Study population. The sample comprised TYA aged 15-24 years, inclusive, drawn from all GP practices contributing to the CPRD since it was established on 1 January 1988 to 31 December 2010. Inclusion criteria and case-control definitions are as described previously (Dommett, 2013).

Symptoms and consultations. Consultations in the 12 months before diagnosis were identified. Libraries of codes representing individual features of possible cancer in TYA were assembled using established methodology (Dommett et al, 2012, 2013). Acne was considered to be unrelated to cancer and was included as a control condition to identify any recording bias (patients with cancer may attend more frequently, giving more opportunities for symptom recording).

Analysis. The magnitudes of associations of symptoms and patterns of consultation frequency with cancer were identified using univariable conditional logistic regression. Only variables occurring in $\geqslant 2 \%$ of either cases or controls, and with a univariable $P$-value $\leqslant 0.1$ entered the multivariable analyses (Hamilton, 2009). We used a 'conservative' $P$-value of $<0.01$ for retention in the final model, to avoid false-positive associations arising from multiple testing. Positive predictive values (PPV) were calculated as described previously (Dommett, 2013).

Sample sizes were predetermined by the total number of cancers in the CPRD, so we performed a power calculation, using a twosided 5\% significance. A study with 300 cases (e.g., lymphoma) each with 13 controls has $\sim 99 \%$ power to identify a change in the prevalence of a variable from $5 \%$ in controls to $10 \%$ in cases. For rarer cancers (e.g., bone), 80 cases had $84 \%$ power to identify a similar change and $97 \%$ power for a change in a commoner variable from $30 \%$ in controls to $50 \%$ in cases.

\section{RESULTS}

In all, 1064 eligible cases and 13206 eligible controls were identified. Their cancer diagnoses are summarised in Supplementary Table 1 online.

Consultation frequency. In the 12 months before diagnosis, cases had a median of five consultations (interquartile range (IQR): 3-9) compared with two (IQR: $0-4)$ in controls $(P<0.001)$. Among cases, $95.2 \%$ had consulted in the year before diagnosis compared with $71.1 \%$ of controls (odds ratio (OR) 9.0; 95\% CI: 6.8-12.1) (Supplementary Table 2 online). Differences in consultation rates were most apparent in the 3 months immediately before diagnosis, cases having a median of three consultations (IQR 1-5) compared with no consultations (IQR $0-1)$ in controls $(P<0.001)$. This difference was consistent across all diagnostic groups in both cases and controls (Supplementary Figure 1 online).

Among cases, $86.9 \%$ had seen their GP in the 3 months before cancer diagnosis compared with $38.8 \%$ of controls (OR: 12.4 ; $95 \%$ CI: $10.3-15.0$ ) (Table 1). Of these, $42.9 \%$ of cases had consulted four times or more compared with $11.5 \%$ of controls (OR: 12.1; 95\% CI: 9.7-15.1). However, the PPV for cancer in a TYA patient consulting four times or more in 3 months was only $0.018 \%$; that is, of 10000 TYA consulting four times or more in 3 months, only around two would be diagnosed with cancer (based on a prior probability of cancer of 0.49 in 10000 in 3 months) (Birch et al, 2002).

Identification of independent associations with cancer. Because of the diversity of diagnoses in our cohort, symptom analysis was limited to four predefined disease groups: leukaemia (annual incidence: 0.21 per 10000 ); lymphoma (annual incidence: 0.47 per 10000 ); CNS tumours (annual incidence: 0.17 per 10000); and bone/soft tissue sarcoma (annual incidence: 0.21 per 10000 ) (Birch et al, 2002). The multivariable models for each group are shown in Table 2.

Four features remained in the final model for leukaemia, of which lympadenopathy had the highest PPV of 1.5 per 10000 (95\% CI: 0.4-5.78).

Four features remained in the final model for lymphoma, of which lump/mass/swelling of the head and neck had the highest PPV of 50.34 per 10000 (95\% CI: 6.96-367.86). The second highest PPV was for lymphadenopathy followed by lump/mass/swelling

Table 1. The association between the number of consultations ${ }^{\mathrm{a}}$ and a diagnosis of cancer

\begin{tabular}{|c|c|c|c|c|c|c|c|}
\hline \multirow[b]{2}{*}{$\begin{array}{l}\text { Number of } \\
\text { consultations }\end{array}$} & \multicolumn{2}{|c|}{$\begin{array}{c}\text { Case } \\
\mathbf{N}=1064\end{array}$} & \multicolumn{2}{|c|}{$\begin{array}{c}\text { Control } \\
N=13206\end{array}$} & \multirow[b]{2}{*}{$O^{b}$} & \multirow[b]{2}{*}{ Likelihood ratio } & \multirow[b]{2}{*}{$\begin{array}{l}\text { Positive predictive } \\
\text { value (per 10000) } \\
(95 \% \mathrm{Cl})\end{array}$} \\
\hline & Freq. & $\%^{c}$ & Freq. & $\%^{c}$ & & & \\
\hline \multicolumn{8}{|c|}{$0-3$ months before index date } \\
\hline No consultatios & 139 & 13.06 & 8071 & 61.12 & 1.0 & & \\
\hline With consultations & 925 & 86.94 & 5135 & 38.88 & $12.4(10.3-15.0)$ & 2.24 & $1.1(1.07-1.14)$ \\
\hline 1 & 195 & 21.08 & 2860 & 55.70 & 1.0 & & \\
\hline 2 & 190 & 20.54 & 1150 & 22.40 & $2.6(2.1-3.2)$ & 0.92 & $0.45(0.39-0.52)$ \\
\hline 3 & 143 & 15.46 & 532 & 10.36 & $4.5(3.5-5.8)$ & 1.49 & $0.73(0.62-0.87)$ \\
\hline 4 or more & 397 & 42.92 & 593 & 11.55 & $12.1(9.7-15.1)$ & 3.72 & $1.83(1.65-2.04)$ \\
\hline \multicolumn{8}{|c|}{$\begin{array}{l}\text { Abbreviations: } \mathrm{Cl}=\text { confidence interval; Freq. }=\text { frequency; } \mathrm{GP}=\text { general practitioner; } \mathrm{OR}=\text { odds ratio. } \\
\text { a All primary care consultations including out of hours and telephone consultations. } \\
\mathrm{b}_{\text {Represents the odds of being diagnosed with cancer given more consultations with the } \mathrm{GP} ; \text {; computed using conditional logistic regression. }} \\
\mathrm{c}_{\text {For categories } 1,2,3 \text { and } 4 \text { or more, proportions reflect only patients with consultations. }}\end{array}$} \\
\hline
\end{tabular}


Table 2. Multivariable analysis of the features of specific TYA cancers: (A) leukaemia, (B) lymphoma, (C) CNS tumours and (D) bone tumour/soft tissue sarcoma

(A) Leukaemia

\begin{tabular}{|c|c|}
\hline $\begin{array}{c}\text { Cases } \\
(\mathbf{N}=143)\end{array}$ & $\begin{array}{c}\text { Control } \\
(\mathbf{N}=1799)\end{array}$ \\
\hline
\end{tabular}

\begin{tabular}{|c|c|c|c|c|c|c|c|c|c|c|c|}
\hline Symptom ${ }^{a}$ & Freq. & $\%$ & Freq. & $\%$ & OR & $\begin{array}{c}95 \% \\
\text { Confidence } \\
\text { interval }\end{array}$ & $\boldsymbol{P}$-value & LR & $\begin{array}{c}95 \% \\
\text { Confidence } \\
\text { interval }\end{array}$ & $\begin{array}{l}\text { PPV (per } \\
10000)\end{array}$ & $\begin{array}{c}95 \% \\
\text { Confidence } \\
\text { interval }\end{array}$ \\
\hline Lymphadenopathy $^{\mathbf{b}}$ & 7 & 4.90 & 3 & 0.17 & 7.65 & $1.55-37.72$ & 0.0124 & 29.35 & $7.67-112.30$ & 1.51 & $0.40-5.78$ \\
\hline Fatigue & 15 & 10.49 & 8 & 0.44 & 12.69 & $4.48-35.96$ & $<0.0001$ & 23.59 & $10.17-54.69$ & 1.21 & $0.52-2.82$ \\
\hline Bruising & 9 & 6.29 & 5 & 0.28 & 24.72 & $4.71-129.78$ & $<0.0002$ & 22.64 & $7.69-66.67$ & 1.17 & $0.40-3.43$ \\
\hline $\begin{array}{l}\text { Three or more } \\
\text { consultations }\end{array}$ & 74 & 51.75 & 125 & 6.95 & 5.92 & $3.71-9.44$ & $<0.0001$ & 7.45 & $5.91-9.39$ & 0.38 & $0.30-0.48$ \\
\hline
\end{tabular}

(B) Lymphoma

\begin{tabular}{|c|c|}
\hline $\begin{array}{c}\text { Cases } \\
(\mathbf{N}=\mathbf{2 7 0})\end{array}$ & $\begin{array}{c}\text { Control } \\
(\mathbf{N}=\mathbf{3 3 5 0})\end{array}$ \\
\hline
\end{tabular}

\begin{tabular}{|l|c|c|c|c|c|c|c|c|c|c|c|}
\hline & & & & & & $\begin{array}{c}\text { 95\% } \\
\text { Confidence } \\
\text { interval }\end{array}$ & P-value & LR & $\begin{array}{c}\text { 95\% } \\
\text { Confidence } \\
\text { interval }\end{array}$ & $\begin{array}{c}\text { 95\% } \\
\text { PPV (per } \\
\text { 10 000) }\end{array}$ & $\begin{array}{c}\text { Confidence } \\
\text { interval }\end{array}$ \\
\hline $\begin{array}{l}\text { Lump mass swelling } \\
\text { head and neck }\end{array}$ & 35 & 12.96 & 1 & 0.03 & 71.85 & $8.98-575.07$ & 0.0001 & 434.26 & $59.72-3157.62$ & 50.34 & $6.96-367.86$ \\
\hline Lymphadenopathy & 77 & 28.52 & 4 & 0.12 & 184.46 & $40.65-837.06$ & $<0.0001$ & 238.84 & $88.09-647.59$ & 27.75 & $10.26-75.44$ \\
\hline Lump mass swelling & 29 & 10.74 & 15 & 0.45 & 14.08 & $5.33-37.19$ & $<0.0001$ & 23.99 & $13.02-44.19$ & 2.79 & $1.52-5.15$ \\
\hline $\begin{array}{l}\text { Three or more } \\
\text { consultations }\end{array}$ & 175 & 64.81 & 294 & 8.78 & 7.67 & $4.92-11.95$ & $<0.0001$ & 7.39 & $6.42-8.50$ & 0.86 & $0.75-0.99$ \\
\hline
\end{tabular}

(C) CNS tumours

\begin{tabular}{|c|c|c|c|c|c|c|c|c|c|c|c|}
\hline & \multicolumn{2}{|c|}{$\begin{array}{c}\text { Cases } \\
(N=154)\end{array}$} & \multicolumn{2}{|c|}{$\begin{array}{c}\text { Control } \\
(N=1906)\end{array}$} & & & & & & & \\
\hline Symptom $^{a}$ & Freq. & $\%$ & Freq. & $\%$ & OR & $\begin{array}{c}95 \% \\
\text { Confidence } \\
\text { interval }\end{array}$ & $\boldsymbol{P}$-value & LR & $\begin{array}{c}95 \% \\
\text { Confidence } \\
\text { interval }\end{array}$ & $\begin{array}{l}\text { PPV (per } \\
10000)\end{array}$ & $\begin{array}{c}95 \% \\
\text { Confidence } \\
\text { interval }\end{array}$ \\
\hline Seizure & 18 & 11.69 & 4 & 0.21 & 17.5 & $5.12-59.83$ & $<0.0001$ & 55.69 & $19.09-162.52$ & 2.38 & $0.82-6.95$ \\
\hline Headache & 33 & 21.43 & 12 & 0.63 & 18.91 & $7.11-50.25$ & $<0.0001$ & 34.04 & $17.95-64.55$ & 1.45 & $0.77-2.76$ \\
\hline Vomiting & 11 & 7.14 & 5 & 0.26 & 7.31 & $1.65-32.47$ & 0.0089 & 27.23 & $9.58-77.37$ & 1.16 & $0.41-3.31$ \\
\hline Pain & 11 & 7.14 & 20 & 1.05 & 6.11 & $2.25-16.57$ & 0.0004 & 6.81 & $3.32-13.95$ & 0.29 & $0.14-0.6$ \\
\hline $\begin{array}{l}\text { Three or more } \\
\text { consultations }\end{array}$ & 73 & 47.4 & 165 & 8.66 & 3.04 & $1.82-5.09$ & $<0.0001$ & 5.48 & $4.39-6.83$ & 0.23 & $0.19-0.29$ \\
\hline
\end{tabular}

(D) Bone tumours/soft tissue sarcoma

\begin{tabular}{|c|c|c|c|c|c|c|c|c|c|c|c|}
\hline & \multicolumn{2}{|c|}{$\begin{array}{c}\text { Cases } \\
(\mathbf{N}=196)\end{array}$} & \multicolumn{2}{|c|}{$\begin{array}{c}\text { Control } \\
(N=2438)\end{array}$} & & & & & & & \\
\hline Symptom $^{a}$ & Freq. & $\%$ & Freq. & $\%$ & OR & $\begin{array}{c}95 \% \\
\text { Confidence } \\
\text { interval }\end{array}$ & $P$-value & LR & $\begin{array}{c}95 \% \\
\text { Confidence } \\
\text { interval }\end{array}$ & $\begin{array}{l}\text { PPV (per } \\
10000)\end{array}$ & $\begin{array}{c}95 \% \\
\text { Confidence } \\
\text { interval }\end{array}$ \\
\hline $\begin{array}{l}\text { Lump mass } \\
\text { swelling }\end{array}$ & 19 & 9.69 & 3 & 0.12 & 39.62 & $8.17-192.1$ & $<0.0001$ & 78.78 & $23.52-263.91$ & 4.15 & $1.24-13.92$ \\
\hline $\begin{array}{l}\text { Musculoskeletal } \\
\text { symptoms }\end{array}$ & 37 & 18.88 & 26 & 1.07 & 8.37 & $4.18-16.76$ & $<0.0002$ & 17.7 & $10.95-28.61$ & 0.93 & $0.58-1.51$ \\
\hline $\begin{array}{l}\text { Three or more } \\
\text { consultations }\end{array}$ & 86 & 43.88 & 189 & 7.75 & 3.88 & $2.48-6.06$ & $<0.0003$ & 5.66 & $4.59-6.98$ & 0.3 & $0.24-0.37$ \\
\hline Chest pain ${ }^{\mathbf{b}}$ & 5 & 2.55 & 12 & 0.49 & 5.15 & $1.47-17.99$ & 0.0103 & 5.18 & $1.84-14.56$ & 0.27 & $0.1-0.77$ \\
\hline
\end{tabular}


below neck excluding abdomen, and it is presumed that all three of these features are likely to represent lymphadenopathy. When lump/mass/swelling of the head and neck, lymphadenopathy and lump/mass/swelling below neck excluding abdomen are combined as a single symptom the PPV is 9.03 per 10000 (95\% CI: 5.73-14.25).

The CNS tumour model contained five features, with seizure having the highest PPV of 2.38 per 10000 (95\% CI: 0.82-6.95). In this group, $8.4 \%$ of cases had visual symptoms, but a PPV could not be calculated as no controls had this feature.

Four variables were independently associated with bone/soft tissue sarcomas, with lump/mass/swelling below neck, excluding abdomen, having the highest PPV of 4.15 per 10000 (95\% CI: 1.24-13.92).

The OR and LR for our control condition, acne, were 1.32 (95\% CI: 0.8-2.19) and 1.31 (95\% CI: 0.8-2.14), respectively, indicating little evidence of recording bias.

\section{DISCUSSION}

This is the first study of TYA cancer to use prospectively collected primary care data. The distribution of cancers was largely representative of the diagnoses seen in TYA, with lymphoma the most common diagnosis overall (25.4\%). We chose to study symptoms and consultations in the 3 months before a diagnosis. This was a practical compromise, being a period over which it is clinically reasonable for a GP to monitor symptoms.

Teenagers and young adults with cancer see their doctors more frequently than controls, particularly in the 3 months before diagnosis. Even so, because TYA cancer is rare, the absolute risk of cancer in a patient consulting four or more times is only 1.8 per 10000 . The consultation rates observed are consistent with retrospective case note analyses (Fern, et al, 2011) and patient reports (Lyratzopoulos et al, 2012; Smith et al, 2007). The high percentage of patients with multiple consultations may represent the complexity of a cancer diagnosis in this age group and supports advice advocating referral if a patient attends several times with the same problem, without a clear diagnosis (National Institute for Health and Clinical Excellence, 2005).

The use of electronic primary care records has limitations as it is well recognised that GPs preferentially record diagnoses as opposed to unexplained symptoms. Under-recording should not affect likelihood ratios (which underpin PPVs) as long as it is consistent between cases and controls, but may lead to an overestimation of PPVs, and they will only remain valid if GP recording and patient consultation behaviour do not change with time (Hamilton, 2012; Shapley et al, 2010).

Our findings confirm the clinical significance of the commonly perceived symptoms of cancer in this age group, as expected symptom patterns emerged for the different diagnostic groups closely matching reports from secondary care. Absolute risks of specific cancers with symptoms have not been estimated previously, although we expected them to be small. Yet, despite the small absolute risks, some features substantially altered the prior probability of a subsequent diagnosis of cancer. The presence of a lump, mass or swelling of the head and neck increased the prior probability of lymphoma from 0.12 per 10000 in any 3-month period to a posterior probability of 50.3 per 10000 , a more than 400 -fold increase in probability. Of note, visual symptoms were not recorded in controls, but were frequent in CNS tumours, implying that investigation is clearly appropriate.

As TYA cancer diagnosis is rare, PPVs will never be particularly high; thus, the question for primary care remains: should a raised relative risk trigger investigation, even when the absolute risk is very small? We believe the seriousness of TYA cancer, coupled with the high potential for cure, justifies investigation at a lower level of probability than might be considered appropriate for later onset adult cancers. Safety-netting procedures are particularly appropriate where, for example, non-resolving musculoskeletal symptoms follow a minor sports injury, may be indicative of a bone/soft tissue sarcoma. This may be especially relevant in this age group as TYAs evolve towards independent health-careseeking behaviour.

\section{CONCLUSION}

The perception of delay in diagnosis in TYA can have major implications on their subsequent cancer journey. The symptoms identified for common cancers in this age group are not unexpected, but some substantially alter the prior probability of a cancer diagnosis. NICE guidance for recognition of suspected cancer is currently being updated in the United Kingdom and the symptoms reported here should enhance the credibility of new recommendations, as they derive from primary care data. Further studies of TYA consultation behaviour and of how symptoms are interpreted both by the GP and the patient are required to fully understand their impact on time to diagnosis, and on how this can be minimised.

\section{ACKNOWLEDGEMENTS}

RMD is funded by the National Institute for Health Research (NIHR). WH was, in part, funded by an NIHR postdoctoral fellowship. This study is based on data from the Full Feature Clinical Practice Research Datalink (CPRD) obtained under licence from the UK Medicines and Healthcare Products Regulatory Agency (MHRA). Access to the CPRD was funded through the Medical Research Council (MRC) licence agreement with the UK Medicines and Healthcare Products Regulatory Agency. The conduct of this study was approved by the Independent Scientific Advisory Committee (ISAC) of the MHRS (Protocol 10_056A) and the University of Bristol (reference: 35515).

\section{CONFLICT OF INTEREST}

The authors declare no conflict of interest.

DISCLAIMER

The interpretation and conclusions contained in this study are those of the author/s alone.

\section{REFERENCES}

Birch JM, Alston RD, Kelsey AM, Quinn MJ, Babb P, McNally RJ (2002) Classification and incidence of cancers in adolescents and young adults in England 1979-1997. Br J Cancer 87(11): 1267-1274.

Clinical Practice Research Datalink (2011) Clinical Practice Research Datalinkavailable at http://www.cprd.com (accessed on 18 December 2012).

Department of Health (2007) Cancer Reform Strategy: Achieving Local Implementation - Second Annual Report. Department of Health: London. Department of Health (2011) Improving Outcomes: A Strategy for Canceravailable at http://www.dh.gov.uk/prod_consum_dh/groups/ dh_digitalassets/documents/digitalasset/dh_123394.pdf (accessed on 20 September 2011). 
Dixon-Woods M, Findlay M, Young B, Cox H, Heney D (2001) Parents' accounts of obtaining a diagnosis of childhood cancer. Lancet 357(9257): 670-674.

Dommett RM, Redaniel MT, Stevens MC, Hamilton W, Martin RM (2012) Features of childhood cancer in primary care: a population-based nested case-control study. Br J Cancer 106(5): 982-987.

Dommett RM, Redaniel T, Stevens MC, Martin RM, Hamilton W (2013) Risk of childhood cancer with symptoms in primary care: a population-based case-control study. Br J Gen Pract 63(606): 22-29.

Fern LA, Campbell C, Eden TO, Grant R, Lewis I, Macleod U, Weller D, Whelan J (2011) How frequently do young people with potential cancer symptoms present in primary care? Br J Gen Pract 61(586): e223-e230.

Hamilton W (2012) Computer assisted diagnosis of ovarian cancer in primary care. BMJ 344: d7628.

Hamilton W, Lancashire R, Sharp D, Peters TJ, Cheng K, Marshall T (2009) The risk of colorectal cancer with symptoms at different ages and between the sexes: a case-control study. BMC Med 7: 17.

Larsen MB, Hansen RP, Olesen F, Vedsted P (2011) Patients' confidence in their GP before and after being diagnosed with cancer. $\mathrm{Br} J$ Gen Pract 61(586): e215-e222.
Lyratzopoulos G, Neal RD, Barbiere JM, Rubin GP, Abel GA (2012) Variation in number of general practitioner consultations before hospital. Lancet Oncol 13(4): 353-365.

National Institute for Health and Clinical Excellence (2005) National Institute for Health and Clinical Excellence. Referral guidelines for suspected canceravailable at http://www.nice.org.uk/nicemedia/live/10968/29814/ 29814.pdf (accessed on 27 September 2011).

Shapley M, Mansell G, Jordan JL, Jordan KP (2010) Positive predictive values of $\geqslant 5 \%$ in primary care for cancer: systematic review. Br J Gen Pract 60(578): e366-e377.

Shephard EA, Stapley S, Neal RD, Rose P, Walter FM, Hamilton WT (2012) Clinical features of bladder cancer in primary care. Br J Gen Pract 62(602): e598-e604.

Smith S, Davies S, Wright D, Chapman C, Whiteson M (2007) The experiences of teenagers and young adults with cancer - results of 2004 conference survey. Eur J Oncol Nurs 11(4): 362-368.

Stapley S, Peters TJ, Neal RD, Rose PW, Walter FM, Hamilton W (2012) The risk of pancreatic cancer in symptomatic patients in primary care: a large. Br J Cancer 106(12): 1940-1944.

Supplementary Information accompanies this paper on British Journal of Cancer website (http://www.nature.com/bjc) 